\title{
STUDI KOLONISASI FUNGI MIKORIZA ARBUSKUAR PADA GAHARU (Gyrinops versteegii) DENGAN SUMBER INOKULAN RIZOSFER PERKEBUNAN GAHARU
}

\author{
Hidayat Wicaksono ${ }^{1}$, I Gde Adi Suryawan Wangiyana ${ }^{1}$, Wahyu Yuniati Nizar ${ }^{1}$ \\ ${ }^{1}$ Fakultas IImu Kehutanan, Universitas Nusa Tenggara Barat, dede.consultant@gmail.com .
}

\section{INFO ARTIKEL}

RiwayatArtikel:

Diterima: 24- 05-2019

Disetujui: 27-08-2019

\section{Kata Kunci:}

Gaharu

Mikoriza

Rizosfer

Perkebunan

\section{A. LATAR BELAKANG}

Gyrinops versteegii merupakan gaharu endemik asal pulau Lombok yang memiliki nilai ekonomis tinggi. Spesies ini tersebar dibeberapa wilayah di Pulau Lombok. Habitat alami gaharu jenis ini adalah di wilayah hutan Senaru Kabupaten Lombok Utara ${ }^{1}$. Selain
ABSTRAK

Abstrak: Penelitian ini bertujuan untuk mengamati kemelimpahan spora mikoriza serta kolonisasi mikoriza pada akar G. versteegii di perkebunan gaharu daerah Langko, Kekait dan Pejaring. Sampel rizosfer diambil dari kedalaman $0 \mathrm{~cm}-20 \mathrm{~cm}$. Ekstraksi spora dilakukan dengan kombinasi metode filtrasi dan sentrifugasi. Preparasi sampel akar $G$. versteegii dilakukan dengan perendaman $\mathrm{KOH} 10 \%$ dilanjutkan dengan Perendaman $\mathrm{HCl} 2 \%$ dan pencucian akuades. Pengamatan kolonisasi akar menggunakan pewarnaan laktogliserol tripam blue 0,05\%. Data populasi spora mikoriza dan kolonisasi akar dianalisis Dengan ANOVA, BNJ dan Standar error. Berdasarkan hasil perhitungan jumlah spora, lokasi desa Pejaring mempunyai jumlah spora tertinggi namun tidak berbeda nyata dengan lokasi Kekait. Jumlah spora mikoriza pada lokasi desa Langko adalah yang terendah namun daerah in merupakan lokasi peresentase kolonisasi akar tertinggi dibandingkan dengan lokasi lainnya Dapat disimpulkan bahwa jumlah spora dan koloniasi akar pada tiap lokasi saling berbanding terbalik (korelasi negative) sehingga menunjukkan hubungan symbiosis yang unik antara mikoriza dan $G$. versteegii

\begin{abstract}
The aim of this research was to observed the abundance of mycorrhiza spore and mycorrhiza colonization on $G$. versteegii's root at agarwood plantation on Langko, Kekait and Pejaring. Rhizosphere samples were taken from $0 \mathrm{~cm}-20 \mathrm{~cm}$ of depth. Spore extraction was carried by combination of filtration and centrifugation methods. G. versteegii roots were soaked with $10 \% \mathrm{KOH}$ continued by $2 \% \mathrm{HCl}$ then were rinsed by distilled water. Lactoglycerol trypan blue 0,05\% were used as dye on root colonization observation. Mycorrhiza spore population and root colonization data were analyzed by ANOVA, HSD and Error Standard. Rhizosphere of Pejaring has the highest number of mycorrhiza spore but not significantly different from Rhizosphere of Kekait. Langko rhizosphere has the smallest number of mycorrhiza spore population. On the other hand, this place has the highest mycorrhiza colonization percentage among the others. It could be concluded that Mycorrhiza spore population has negative correlation with mycorrhiza root's colonization which shows unique symbiotic between mycorrhiza and $G$. versteegii..
\end{abstract}

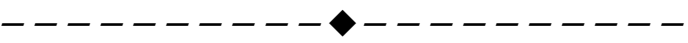

itu, sepesies ini juga banyak dibudidayakan di perkebunan gaharu di daerah Lingsar Kabupaten Lombok Barat $^{2}$ serta di Perkebunan gaharu Desa Pejaring Kabupaten Lombok Timur 3.

Dengan nilai ekonomis yang tinggi, komoditi gaharu spesies ini gencar dibudidayakan di wilayah Pulau Lombok. Terlebih lagi, kegiatan budidaya 
merupakan salah satu cara konservasi yang tepat terkait semakin terancamnya populasi alam gaharu spesies ini. Hal ini dibuktikan dari masuknya spesies $G$. versteegii kedalam daftar CITES appendix II 4 . Artinya spesies ini sebagai komoditi dagang dibatasi hanya boleh menggunakan subjek dari hasil budidaya, bukan spesies alam. Oleh karena itulah kegiatan budidaya terhadap spesies ini penting untuk digalakkan.

Budidaya gaharu spesies G. versteegii membutuhkan media tanam yang mampu mendukung pertumbuhan optimal dari spesies ini. Salah satu kriteria media tanam yang baik adalah memiliki tingkat kesuburan tinggi. Terdapat korelasi antara populasi mikoriza dengan tingkat kesuburan tanah. Hal ini semakin menguatkan teori bahwa mikoriza memiliki peranan esensial dalam budidaya tanaman. Salah satunya adalah tanaman gaharu spesies Gyrinops versteegii 5 .

Asosiasi mikoriza pada proses pembibitan tanaman penghasil gaharu telah banyak dilakukan pada kelompok genus Aquilaria namun tidak demikian halnya dengan Gyrinops versteegii. Kompatibilitas antara mikoriza dengan tanaman gaharu sebagai inang merupakan hal yang esensial ${ }^{6}$. Oleh karena itu, sebaiknya sumber inokulan dari mikoriza diambil dari lokasi yang menjadi habitat alami ataupun habitat artifisial dari tanaman G. versteegii

Studi terkait asosiasi fungi Mikoriza Arbuskular pada habitat alami G. versteegii di Hutan Senaru telah dilakukan dengan hasil yang cukup memuaskan ${ }^{1}$. Studi ini perlu dikembangkan dengan memilih sumber inokulan selain habitat alami. Salah satunya adalah dari wilayah perkebunan gaharu terutama di diwilayah pulau Lombok. Dengan demikian akan diperoleh data komparasi antara mikoriza pada hutan sebagai habitat alami dengan mikoriza pada perkebunan sebagai habitat artifisial.

Oleh karena itulah penelitian ini bertujuan untuk mengamati kemelimpahan spora mikoriza serta kolonisasi mikoriza pada akar G. versteegii di perkebunan gaharu daerah Langko, Kekait dan Pejaring.

\section{B. METODE PENELITIAN}

Penelitian ini dilakukan dari bulan Mei 2019 - Juni 2019. Pengambilan sampel rizosfer dilakukan di perkebunan gaharu di tiga wilayah berbeda yaitu: Desa Kekait, Desa Langko dan Desa Pejaring. Sementara itu proses ekstraksi spora dan pengamatan kolonisasi mikoriza pada akar G. verstegeii dilakukan di laboratorium terpadu Fakultas Ilmu Kehutanan Universitas Nusa Tenggara Barat. Penelitian ini mengikuti tahapan secara sistematis seperti ditunjukkan oleh Gambar 1.

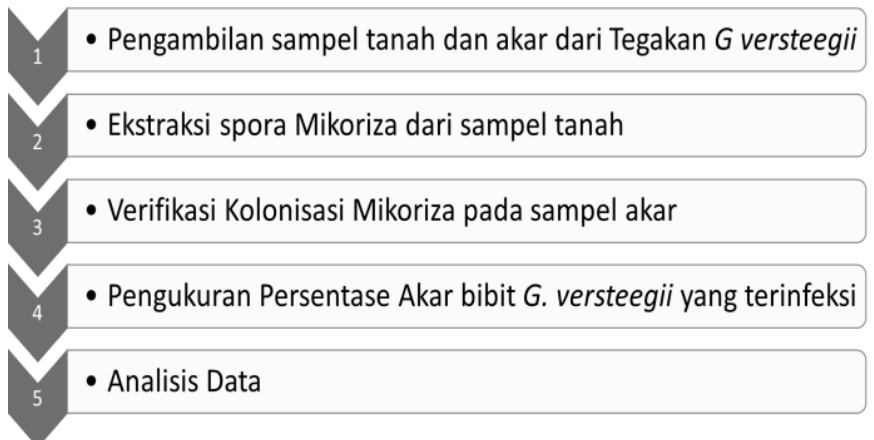

Gambar 1. Urutan Tahapan Kegiatan Penelitian

\section{Pengambilan Sampel}

Sampel tanah diambil dari tegakan G. versteegii di 3 lokasi berbeda, yaitu: Desa Kekait, Desa Langko dan Desa Pejaring (Tabel 1). Sebanyak 3 sampel diambil dari tiap lokasi tersebut. Lokasi yang dijadikan tempat sampling dipasang plot percobaan berukuran $1 \mathrm{~m} \times 1 \mathrm{~m}$. Sebanyak $1 \mathrm{~kg}$ sampel rizozfer dari tiap plot diambil dari kedalaman $\mathrm{O}-20 \mathrm{~cm}$ untuk ekstraksi spora mikoriza. Sementara itu sampel akar Tegakan G. versteegii juga diambil dari plot yang sama dengan pengambilan sampel tanah untuk verifikasi keberadaan Mikoriza pada tegakan G. versteegii.

Tabel 1

Titik koordinat Pengambilan Sampel

\begin{tabular}{lll}
\hline Lokasi & Lintang & Bujur \\
\hline Kekait & $8^{\circ} 31^{\prime} 19,4$ "S & $116^{\circ} 06^{\prime} 16,1^{\prime \prime} \mathrm{E}$ \\
\hline Langko & o8 $^{\circ} 33^{\prime} 34,3^{\prime \prime} \mathrm{S}$ & $116^{\circ} 09^{\prime} 28,3^{\prime \prime} \mathrm{E}$ \\
\hline Pejaring & o8 $^{\circ} 42^{\prime} 24,9^{\prime \prime} \mathrm{S}$ & $116^{\circ} 27^{\prime} 14,6^{\prime \prime} \mathrm{E}$ \\
\hline
\end{tabular}

\section{Ekstraksi Spora Mikoriza dari Sampel}

Ekstraksi spora mikorza dari sampel tanah menggunakan metode Wangiyana dan Malik (2018) ${ }^{1}$ dengan beberapa modifikasi. Sampel tanah dihaluskan dengan cara daayak agar spora dapat terbebas dari partikel tanah. Selanjutnya sebanyak 100 gr sampel tanah dimasukkan dalam botol $1 \mathrm{~L}$ dan ditambahkan air sebanyak $500 \mathrm{~mL}$ sambil dikocok. Sampel tanah dibiarkan mengendap kemudian bagian supernatan disaring dengan saringan ukuran 100 mikron dan 38 mikron. Filtrat selanjutnya disentrifugasi dengan kecepatan $2000 \mathrm{rpm}$ selama 20 menit. Bagian supernatan selanjutnya ditambahkan larutan sukrosa 50\% dan disentrifugasi kembali dengan kecepatan 2000 rpm selama 20 menit. Bagian supernatan disaring dengan mengunakan kertas saring Advantec No. 2 dan siap diamati menggunakan mikroskop stereo.

\section{Pengamatan kolonisasi mikoriza pada sampel akar}

Sampel akar dicuci terlebih dahulu hingga bersih. Selanjutnya sampel akar direndam dalam $\mathrm{KOH} 10 \%$ selama 12 jam. Setelah akar dicuci bersih selanjutnya 
direndam kembali dalam larutan $\mathrm{HCl} 2 \%$ selama 30 menit. Setelah akar dicuci bersih, dilakukan pengecatan dengan trypan blue $0,05 \%$ dalam laktogliserol. Selanjutnya potongan akar dicat dan dibilas dalam larutan glisereol 50\%7. Pengamatan kolonisasi Mikoriza pada akar G. versteegii dilakukan untuk memastikan bahwa spora Mikoriza yang diekstrak dari rizosfer sekitar perakaran merupakan mikoriza indigenus yang bersimbiosis dengan $G$. versteegii.

\section{Pengukuran Persentase Akar bibit G. versteegii yang terinfeksi}

Salah satu parameter yang menunjukkan tingkat simbiosis antara mikoriza dengan inangnya adalah dengan menghitung derajat kolonisasi fungi Mikoriza Arbuskular pada bagian akar. Oleh karena itulah kolonisasi mikoriza merupakan salah satu parameter penting dalam penelitian ini. Perhitungan derajat kolonisasi pada akar $G$. versteegii yang diperoleh dari 3 lokasi dilakukan dengan metode Gridline intersect ${ }^{7}$. Selanjutnya perhitungan persentase akar yang terinfeksi dilakukan berdasarkan rumus sebagai berikut:

$$
\% \text { kolonisasi }=\frac{\text { Total } \% \text { kolonisasi }}{\text { Total potongan akar }} \times 100 \%
$$

\section{Analisis Data}

Data populasi spora dan kolonisasi mikoriza pada akar G. versteegii di setiap lokasi pengambilan sampel dianalisis dengan ANOVA pada $\alpha=0,05$. Jika terdapat perbedaan signikan pada lokasi berbeda, dilanjutkan dengan Uji Beda Nyata Jujur (BNJ) pada $\alpha=0,05$. Perbedaan populasi spora mikoriza pada lokasi berbeda juga dianalisis standar error pada $\alpha=0,05$. Semua pengolahan data dilakukan dengan program Co-stat 6 For Windows.

\section{HASIL DAN PEMBAHASAN}

\section{Populasi Spora Mikoriza}

Perhitungan populasi spora mikoriza menunjukkan bahwa terdapat variasi populasi mikoriza pada tiap lokasi. Pada lokasi yang sama sekalipun terdapat variasi jumlah spora mikoriza. Untuk lebih jelasnya dapat dilihat pada Tabel 2. Dengan adanya variasi inilah perlu dilakukan uji ANOVA untuk analisis lebih lanjut.

Tabel 2

Hasil Perhitungan Jumlah Spora pada Rizosfer Perkebunan Gaharu di 3 lokasi berbeda

\begin{tabular}{|cccc}
\hline \multicolumn{4}{c|}{ Lokasi Pejaring } \\
\hline \multirow{2}{*}{ Bidang Pandang } & \multicolumn{3}{c|}{ Jumlah Spora } \\
\cline { 2 - 4 } & Sampel I & Sampel II & Sampel III \\
\hline 1 & 5 & 3 & 1 \\
\hline 2 & 1 & 1 & 1 \\
\hline 3 & 2 & 3 & 2 \\
\hline
\end{tabular}

\begin{tabular}{|c|c|c|c|}
\hline 4 & 1 & 3 & 4 \\
\hline 5 & 1 & 1 & 1 \\
\hline 6 & 2 & 2 & 1 \\
\hline Total & 12 & 13 & 10 \\
\hline \multicolumn{4}{|c|}{ Lokasi Kekait } \\
\hline \multirow[t]{2}{*}{ Bidang Pandang } & \multicolumn{3}{|c|}{ Jumlah Spora } \\
\hline & Sampel I & Sampel II & Sampel III \\
\hline 1 & 3 & 1 & 3 \\
\hline 2 & 2 & 1 & 3 \\
\hline 3 & 2 & 1 & 1 \\
\hline 4 & 1 & 2 & 2 \\
\hline 5 & 3 & 1 & 2 \\
\hline 6 & 1 & 2 & 1 \\
\hline Total & 12 & 8 & 12 \\
\hline \multicolumn{4}{|c|}{ Langko } \\
\hline \multirow[t]{2}{*}{ Bidang Pandang } & \multicolumn{3}{|c|}{ Jumlah spora } \\
\hline & Sampel I & Sampel II & Sampel III \\
\hline 1 & 1 & 1 & 1 \\
\hline 2 & 2 & 1 & 1 \\
\hline 3 & 1 & 1 & 1 \\
\hline 4 & 1 & 2 & 1 \\
\hline 5 & 1 & 2 & 1 \\
\hline 6 & 2 & 2 & 2 \\
\hline Total & 8 & 9 & 7 \\
\hline
\end{tabular}

Jumlah spora setiap bidang pandang tergolong cukup rendah. Jumlah maksimal spora pada satu bidang pandang yang tercatat adalah sebanyak 5 spora. Spora mikoriza tersebut tervisualisasi dengan jelas dibawah pengamatan menggunakan mikroskop stereo perbesaran 40x (Gambar 2).

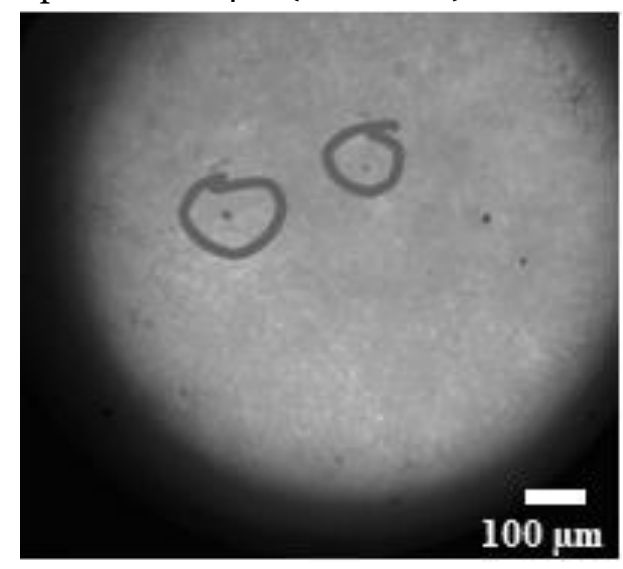

Gambar 2. Spora Mikoriza Arbuskular pada rizozfer perkebunan gaharu

Berdasarkan tabel hasil ANOVA, terlihat bahwa lokasi berbeda secara signifikan berpengaruh terhadap jumlah spora. Dalam hal ini, populasi mikoriza arbuscular dalam wujud spora memiliki kelimpahan berbeda - beda di tiga lokasi pengamtan meliputi: Kekait, Pejaring dan Langko. Untuk mengetahui pada lokasi mana yang memiliki signifikansi terhadap lokasi lainnya, dilakukan uji lanjut. Uji lanjut yang digunakan adalah Uji Beda Nyata Jujur.

Selanjutnya Berdasarkan Uji Beda Nyata Jujur diperoleh hasil bahwa populasi spora mikoriza tertinggi berada pada lokasi Pejaring. Akan tetapi 
rerata jumlah spora pada lokasi Pejaring tidak berbeda signifikan dengan lokasi Kekait. Jumlah rerata spora pada lokasi Pejaring berbeda nyata dengan lokasi Langko yang merupakan lokasi dengan populasi spora terendah. Untuk lebih jelasnya dapat dilihat pada Tabel 3.

\section{Tabel 3}

Hasil uji BNJ Terhadap Populasi Spora pada 3 Lokasi

\begin{tabular}{cccc}
\hline Peringkat & Lokasi & Rerata & Notasi \\
\hline 1 & Pejaring & 11,67 & $\mathrm{a}$ \\
\hline 2 & Kekait & 10,67 & $\mathrm{ab}$ \\
\hline 3 & Langko & 8,00 & $\mathrm{~b}$
\end{tabular}

Keterangan: notasi berbeda menunjukkan berbeda signifikan pada $\alpha=0,05$

Hasil Uji BNJ ini dapat dikonfirmasi dengan menggunakan analisis Standar Error. Gambar 3 menunjukkan grafik badang yang diberi error bar menggunakan standar error. Hasilnya sama seperti uji BNJ, yaitu tidak ada perbedaan signifikan populasi spora pada lokasi Pejaring dan Kekait. Populasi spora pada kedua wilayah itu berbeda dengan populasi spora pada lokasi Langko.

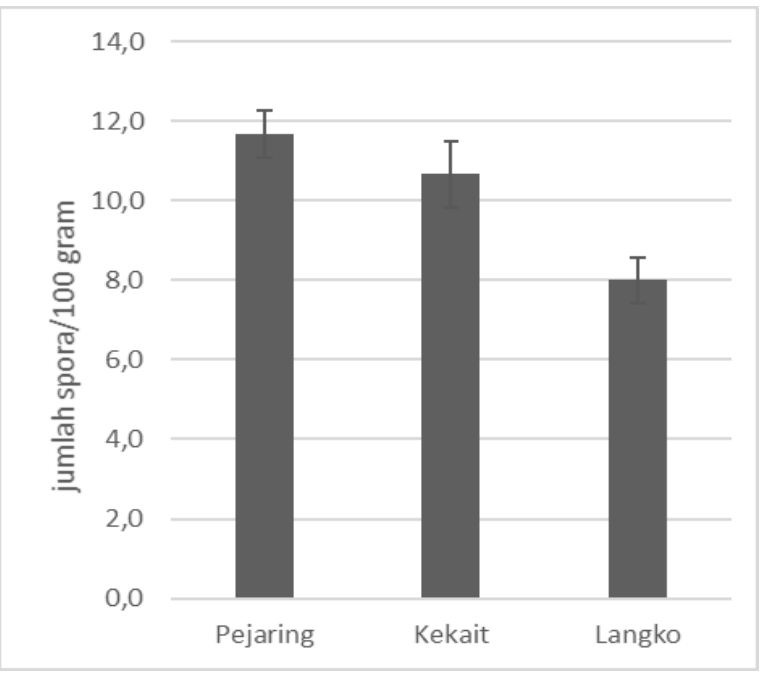

Gambar 3. Analisis Standar Error Populasi Spora Mikoriza pada 3 Lokasi Berbeda

Populasi spora pada 3 lokasi perkebunan gaharu tersebut tergolong cukup rendah. Idealnya jumlah spora pada rizosfer mencapai 100 spora per 100 gram sampel ${ }^{8}$. Bahkan pada beberapa area pembibitan, jumlah spora mikoriza dapat mencapai 300 spora per 100 gram tanah 9 . Meskipun jumlah spora mikoriza di perkebunan agharu relatif rendah, namun hal ini bukan berarti lokasi tersebut tidak dapat dijadikan sebagai lokasi isolasi mikoriza indigenus untuk gaharu. Hal ini dikarenakan populasi spora mikoriza bisa diperbanyak pada media buatan di laboratorium. Rendahnya populasi mikoriza pada 3 lokasi perkebunan gaharu tersebut justru dapat dijadikan peluang untuk mengembangkan mikoriza indigenus di lokasi tersebut secara intensif karena populasinya tergolong masih rendah.

\section{Kolonisasi Mikoriza pada Akar}

Kolonisasi mikoriza pada akar G. versteegii ditandai dengan adanya lilitan hifa jamur pada bagian korteks akar. Lilitan hifa ini terlihat seperti benang - benang halus yang membelit akar (Gambar 4). Namun tentu saja kolonisasi mikoriza tersebut tidak terdapat pada semua sampel sehingga ada sampel akar yang sama sekali tidak terkolonisasi oleh mikoriza.

Kolonisasi mikoriza pada akar G. versteegii berbeda - beda untuk tiap lokasi perkebunan gaharu. Pada lokasi perkebunan yang sama juga terdapat variasi persentase kolonisasi mikoriza (Tabel 4). Bahkan pada lokasi perkebunan gaharu di Kekait, terdapat sampel akar yang sama sekali tidak dikolonisasi oleh mikoriza (persentase kolonisasi o\%). Variansi seperti ini perlu untuk dianalisis lebih lanjut menggunakan ANOVA.

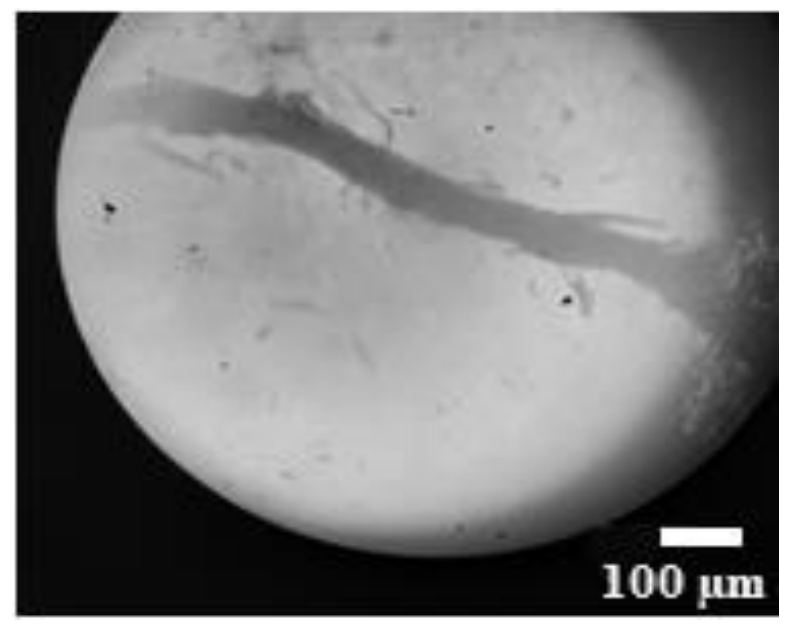

Gambar 4. Akar G. versteegii terinokulasi Hifa Mikoriza

Tabel 4

Persentase Kolonisasi Mikoriza pada 3 Lokasi Perkebunan Gaharu

\begin{tabular}{ccccc}
\hline \multirow{2}{*}{ Lokasi } & \multicolumn{3}{c}{ Persentase Kolonisasi } & \multirow{2}{*}{ Rerata } \\
\cline { 2 - 4 } & sampel I & Sampel II & Sampel III & \\
\hline Pejaring & $20 \%$ & $10 \%$ & $40 \%$ & $23,3 \%$ \\
\hline Kekait & $40 \%$ & $30 \%$ & $0 \%$ & $23,3 \%$ \\
\hline Langko & $60 \%$ & $100 \%$ & $70 \%$ & $76,7 \%$ \\
\hline
\end{tabular}

Berdasarkan hasil ANOVA terhadap kolonisasi mikoriza pada akar G. versteegii terlihat bahwa kolonisasi fungi Mikoriza Arbuskular pada lokasi berbeda secara signifikan berbeda pada taraf $\alpha=$ 0,05. Hal ini menunjukkan bahwa kolonisasi mikoriza dipengaruhi oleh lokasi tumbuh tanaman $G$. 
versteegii sebagai inang. Untuk analisis lebih lanjut terkait kolonisasi mikoriza pada tiap lokasi berbeda dilakukan uji BNJ.

Tabel 5.

Hasil Uji BNJ Terhadap Persentase Kolonisasi Mikoriza pada Akar G. versteegii di 3 Lokasi Berbeda

\begin{tabular}{cccc}
\hline Peringkat & Lokasi & Rerata \% kolonisasi & Notasi \\
\hline 1 & Langko & 76,7 & a \\
\hline 2 & Pejaring & 23,3 & b \\
\hline 3 & Kekait & 23,3 & b \\
\hline
\end{tabular}

Keterangan: notasi berbeda menunjukkan signifikan pada taraf $\alpha=0,05$

Berdasarkan uji BNJ terlihat bahwa persentase kolonisasi mikoriza pada akar G. versteegii paka lokasi Langko berbeda secara signifikan dengan lokasi lainnya (Tabel 5). Sementara itu, pada lokasi Pejaring dan Kekait, kolonisasi fungi Mikoriza Arbuskular pada akar G. versteegii tidak berbeda secara signifikan. Hal ini menunjukkan bahwa lokasi terbaik perkebunan gaharu untuk mempelajari asosiasinya dengan fungi Mikoriza Arbuskular adalah pada lokasi Langko. Perbedaan persentase koloniasi mikoriza pada akar G. versteegii di lokasi Langko cukup tinggi sehingga cukup mencolok ketika disajikan dalam bentuk grafik (Gambar 5).

Jika dianalisis lebih lanjut terdapat korelasi negatif antara jumlah populasi spora mikoriza dengan persentase kolonisasi mikoriza pada akar. Lokasi Pejaring merupakan lokasi yang memiliki populasi spora mikoriza tertinggi pada bagian rizosfernya. Akan tetapi pada lokasi ini, kolonisasi mikoriza pada bagian akar G. versteegii adalah yang terendah dibandingkan lokasi lain. Sebaliknya, Langko merupakan lokasi yang paling sedikit mengandung spora mikoriza pada bagian rizosfernya. Akan tetapi persentase kolonisasi mikoriza pada akar G. versteegii dilokasi ini adalah yang tertinggi dibandingkan dengan lokasi lainnya. Hal ini menunjukkan bahwa asosiasi mikoriza dengan $G$. versteegii pada lokasi Langko lebih erat dibandingkan dengan lokasi lainnya.

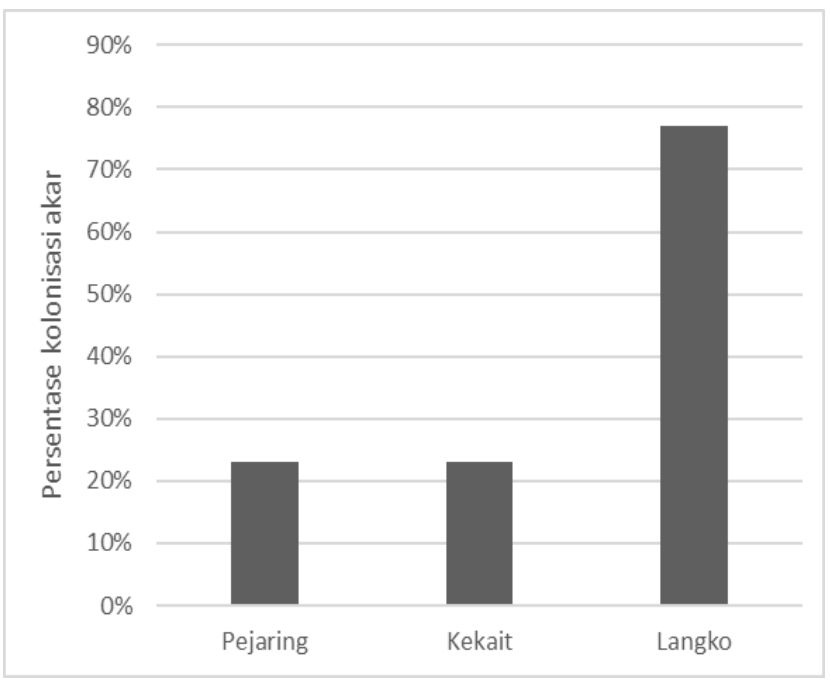

Gambar 5. Persentase Kolonisasi Mikoriza pada Akar G. versteegii di 3 Lokasi Berbeda

Korelasi berbanding terbalik tersebut menunjukkan simbiosis yang unik antara mikoriza dengan G. versteegii. Dalam hal ini, mikoriza lebih memilih untuk mengkolonisasi akar G. versteegii dibandingkan hidup bebas dalam bentuk spora pada rizosfer. Hal ini lah yang menunjukkan saling ketergantungan yang spesifik antara mikoriza dengan G. Versteegii $i^{10}$.

Kolonisasi mikoriza pada akar dapat digunakan sebagai acuan untuk menggambarkan saling ketergantungan antara mikoriza dengan tanaman inang dalam hubungan simbiosis. Semakin tinggi persentase kolonisasi maka semakin tinggi pula saling ketergantungan tersebut. Hal ini dikarenakan masing-masing pihak yang terlibat dalam simbiosis tersebut sama-sama memperoleh keuntungan sehingga akan lebih cenderung untuk bersimbiosis dibandingkan hidup secara soliter ${ }^{10}$.

\section{SIMPULAN DAN SARAN}

Dapat disimpulkan bahwa jumlah spora tertinggi ada pada rizosfer Pejaring namun persentase kolonisasi tertinggi ada pada Langko. Hal ini menunjukkan bahwa koloniasi akar dan populasi spora pada tiap lokasi saling berbanding terbalik atau memiliki korelasi negatif sehingga menunjukkan hubungan symbiosis yang unik antara mikoriza dan G. versteegii.

Disarankan untuk penelitian lanjutan diperlukan proses identifikasi jenis spora mikoriza yang berhasil diisolasi dari setiap lokasi sehingga diperoleh data akurat jika kedepannya akan dilakukan pengembangan mikoriza indigenus pada perkebunan gaharu ( $G$. versteegii). Selain itu, spora tersebut dapat diformulasikan sebagai media tumbuh untuk persemaian benih gaharu (G. versteegii) ataupun media pembibitan sehingga secara langsung dapat menunjukkan manfaat untuk budidaya gaharu secara berkelanjutan 


\section{UCAPAN TERIMA KASIH}

Penulis mengucapkan terima kasih kepada Kepala Laboratorium Terpadu Fakultas Ilmu Kehutanan Universitas Nusa Tenggara Barat dan tenaga laboran yang telah membantu penulis selama menyelesaikan skripsi sehingga menjadi bahan utama penulisan artikel ini

\section{DAFTAR RUJUKAN}

[1] Wangiyana, I G. A. S and Malik, S. "Application of Arbuscular Mycorrhiza from Senaru Forest Rhizosphere for Gyrinops versteegï Germination and Growth”. Biosaintifika, Vol. 10, No. 1, h. $432-438$, Agustus 2018

[2] Wangiyana, I G. A. S dan Sami'un. "Characteristic of Agarwood Tea from Gyrinops versteegii Fresh and Dry Leaves". Jurnal Sangkareang Mataram, Vol 4. No. 2, h. 41 - 44, Juni 2018.

[3] Wangiyana, I G. A. S., Wanitaningish, S. K., Sanjaya, A. "Bioinduksi Gyrinops versteegii Menggunakan Inokulan Berbahan Baku Medium Tauge dengan Berbagai Kedalaman Pengeboran”. Prosiding Seminar Nasional Pertanian Universitas Mataram, Mataram, Indonesia, h. 144 - 152, Januari 2018.

[4] Schmidt, M. S., "Introduction to CITES and Agarwood Overview", Asian Regional Workshop on Agarwood, Jakarta, Indonesia, November 2011.

[5] Syib'il, M. A., Muhibuddin, A., Djauhari, S. "Arbuscular Mycorrhiza Fungi as an Indicator of Soil Fertility", Agrivita, Vol. 35, No 1, h. 44- 53, 2013

[6] Mbaubedari, K. F. "Pengaruh Fungi Mikoriza Arbuskula (FMA) dan Media Tumbuh Terhadap Pertumbuhan Planting Gaharu (Gyrinops versteegii (Gilg) Domke) Hasil Multiplikasi in Vitro", Thesis, Sekolah Pascasarjana Program Studi Ilmu Pengetahuan Kehutanan, Institut Pertanain Bogor, 2011

[7] Wangiyana, W., "Analyzing The Effect of Cropping History on the Relationships Between Arbuscular Mycorrhizas and Crop Growth Using Multiple Regression Analysis With Mixed Categorical and Continuous Independent Variable. Agroteksos, Vol. 19, No. 3, h. 81 88, 2009

[8] Duponnois, R., Plenchette, C., Thioulouse, J., Cadet, P. "The Mycorrhizal Soil Infectivity and Arbuscular Mycorrhizal Fungal Spore Communities in Soils of Different Aged Fallows in Senegalet". Applied Soil Ecology, Vol 17, No. 3, pp. 239 - 251, March 2001

[9] Vilcatoma-Medina, C., Kaschuk, G, Zanette, F. " Colonization and Spore Richness of Arbuscular Mycorrhizal Fungi in Araucaria Nursery Seedlings in Curitiba, Brazil". International Journal of Agronomy, https://doi.org/10.1155/2018/5294295. April 2018.

[10] Madigan, M. T., Martinko, J. M., Stahl, D. A., Clark, D. P. Brock Biology of Microorganisms, Benjamin Cummings, Boston, 2013.

[11] Gange, A. C. and Ayres, R. L. "On the Relation between Arbuscular Mycorrhizal Colonization and Plant Benefit". OIKOS, Vol. 87, No. 3, pp. 615 - 621, December 1999. 